\title{
Poncet's disease: a reactive arthritis secondary to pulmonary tuberculosis
}

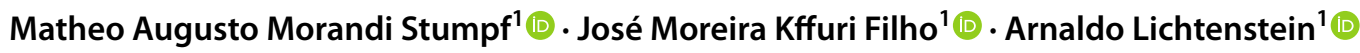

Received: 30 December 2021 / Revised: 26 January 2022 / Accepted: 28 January 2022 / Published online: 2 February 2022

(c) International League of Associations for Rheumatology (ILAR) 2022

\section{Presentation}

A 41-year-old man presented with a 2-month history of cough, weight loss, and fever. He had an antecedent of peptic ulcer disease and was on omeprazole. GeneXpert in sputum confirmed Mycobacterium tuberculosis; the patient received ethambutol, isoniazid, pyrazinamide, and rifampicin single tablet.

After 2 weeks of treatment, he developed arthritis in his right ankle. We opted to start colchicine $0.5 \mathrm{mg}$ twice a day believing in a possible gout flare since hyperuricemia can be a side effect of tuberculostatics. After 5 days of treatment, he returned with an asymmetric polyarthritis (right ankle, knee, wrist, and second to fifth metacarpophalangeal). Laboratory workup showed mild elevation of inflammatory markers, normal complement, negative ANA, ANCA, HIV, hepatitis, VDRL, and rheumatoid factor. We started prednisone $20 \mathrm{mg}$ daily for a possible Poncet's disease and scheduled a knee arthrocentesis for synovial analysis. Unfortunately, the knee arthrocentesis was not performed since the patient had a dramatic improvement with corticosteroids-by the second day, he maintained only arthralgia in the right hand. Therefore, for arthritis documentation, a hand magnetic resonance imaging was done, which revealed multifocal tenosynovitis (Fig. 1). Tuberculostatics drugs were maintained throughout the treatment. Prednisone was withdrawn after 10 days, and the patient did not have any arthritis relapse during follow-up.

\section{Discussion}

Poncet's disease, often known as tuberculous rheumatism, is sterile reactive arthritis caused by tuberculosis infection. The pathogenic mechanism is unknown; however, it is thought that sensitized CD4 + cells induce arthritis due to bacterial antigens that migrate to the joints [1].

There are some diagnostic criteria proposed which include $[2,3]$ the following: evidence of active extra-articular tuberculosis, manifestation in more than one joint (i.e., oligoarthritis in the knees and ankles), lack of axial, vertebral, sacroiliac impairment, unspecific laboratory findings, no chronicity with no articular sequelae, and complete resolution after antituberculous chemotherapy.

Exclusion of other rheumatologic diseases is also warranted, and since arthrocentesis is not always feasible, recent case reports of Poncet's disease are based mainly on the clinical features listed above [4]. Close follow-up is recommended when arthrocentesis is not performed, mainly because septic tuberculous arthritis is a possibility.

In 2013, Rueda et al. published a review article that included 198 cases of Poncet's disease. In their manuscript, the most affected joint were the ankles (63.3\%), followed by knees (58.8\%), wrists (29.1\%), and elbows (23.1\%). Forty percent of the patients presented with oligoarthritis, $27.6 \%$ with polyarthritis, and $24.6 \%$ with monoarthritis [2].

Although rare, a recurrence of arthritis in the following weeks is possible. Usually, joint arthritis resolves in an average of 51.6 days after antituberculous therapy [2]. Symptomatic treatment with corticosteroid or NSAID is an option.

Matheo Augusto Morandi Stumpf

matheoaugusto@hotmail.com

1 Internal Medicine Department, University of São Paulo (USP), Av. Prof Lineu Prestes, São Paulo 2565, 05508-000, Brazil 
Fig. 1 Fat suppressed

T2-weighted scan: (A) axial plane showing tenosynovitis in the third and fourth flexors (arrows). (B) axial plane showing tenosynovitis in III and IV extensor compartments (arrow)

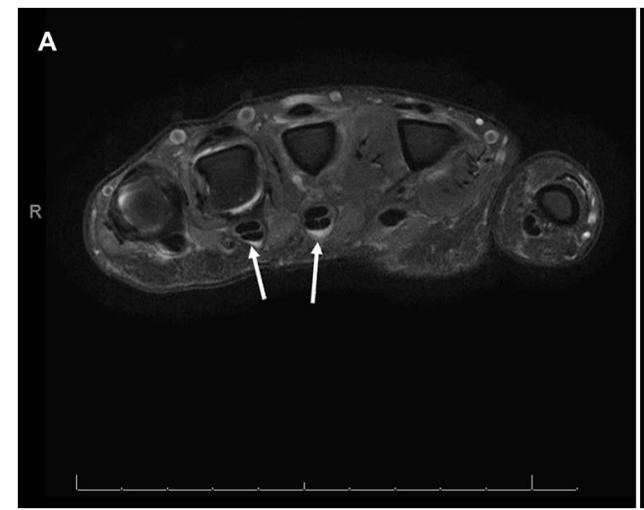

B

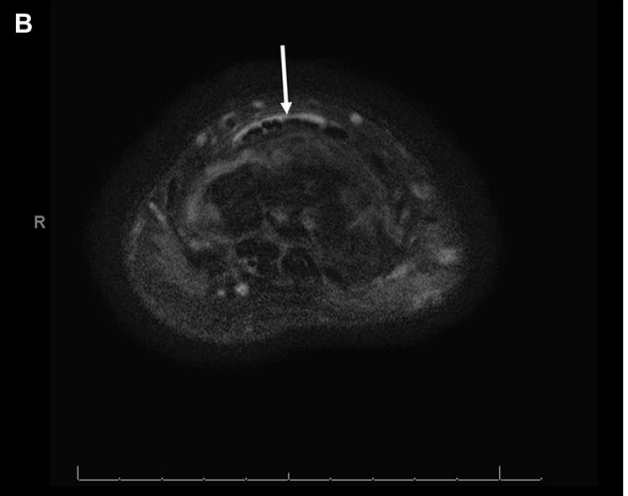

\section{Declarations}

Ethics approval and consent to participate Written informed consent was obtained from the patient for publishing this material.

\section{Disclosures None.}

\section{References}

1. Abdulaziz S, Almoallim H, Ibrahim A, Samannodi M, Shabrawishi M, Meeralam Y, Abdulmajeed G, Banjar G, Qutub W, Dowaikh H (2012) Poncet's disease (reactive arthritis associated with tuberculosis): retrospective case series and review of literature. Clin Rheumatol 31(10):1521-1528
2. Rueda JC, Crepy MF, Mantilla RD (2013) Clinical features of Poncet's disease. From the description of 198 cases found in the literature. Clin Rheumatol 32(7):929-35

3. Sharma A, Pinto B, Dogra S, Sharma K, Goyal P, Sagar V, Dhir V, Sharma S, Singh S (2016) A case series and review of Poncet's disease, and the utility of current diagnostic criteria. Int J Rheum Dis 19(10):1010-1017

4. Arora S, Prakash TV, Carey RA, Hansdak SG (2016) Poncet's disease: unusual presentation of a common disease. Lancet 387(10018):617-618

Publisher's Note Springer Nature remains neutral with regard to jurisdictional claims in published maps and institutional affiliations. 